\title{
Impact of Green Sports on Construction of Sporting Power
}

\author{
Houzhong Jin \& Hongquan Li \\ Sports Economics and Management School, Central University of Finance and Economics \\ Beijing 100081, China \\ E-mail: jinhouzhong@126.com
}

This paper is sponsored by Beijing Planning Project of Philosophy and Social Science (09BaZh126).

\begin{abstract}
The theme of green sports is "harmony and development". In this paper, the author analyzes the impact of green sports on construction of sporting power from dimensions of green sports' consciousness, education, system, service, and cultural, offering references for decision concerning the construction of sporting power.

Keywords: Green sports, Construction, Sporting power

Green sports are sporting activities built by the mutual coordination, interactive care, interdependence, integration, and common development of sports, culture, and ecological environment (Houzhong Jin, 2009, p23). The harmony of human and nature is the physical base of green sports. The harmony of people and people is the social base of green sports. The harmonious development of individuals is the ultimate target of green sports (Te $\mathrm{Bu}, 2007, \mathrm{p} 95-100)$. In the process of further driving China develop from sporting giant to sporting power, we should take the mass sports, competitive sports, school sports, sports industry, and sports soft power as the base, and the construction of green sports as the guide, "with general coordinative thoughts and means, overcome the alienation of sporting activity, and reach the general dynamic harmony which includes the harmonies of human and nature, people and people, and individual" (Yin Guo \& Zhibin Huang, 2005), realizing the integration of green sports' consciousness, education, system, service, and culture, and construction of sporting power.
\end{abstract}

\section{The impact of consciousness of green sports on construction of sporting power}

The construction of sporting power "should take the competitive sports, mass sports, and sports industry as the forerunner, reflecting the general development level of all fields of sports at present, including sports science and technology, physical education, sports culture, and sports grounds, etc." (Xue Qiu, 2010, p10-14). Here, every aspect should display the consciousness of green sports, namely the idea of commitment, globalization, co-existence, and volunteer. As for the consciousness of commitment, in the Olympic Games (2008) Beijing has fulfilled 1.3 billion Chinese's grand commitment to the world by practice, saving valuable "green example" for the construction of sporting power. Today, the green sports' consciousness of commitment has become the "ideal experiment field" for the construction of sporting power, from equity to duty, from theory to practice. As for the consciousness of globalization, Chinese traditional sports have exerted profound effects on modern sports, with the charming values, cultures, thoughts, and behaviors. For example, the ideas of justice, honesty, kindness, and friendliness from sports ethics with Confucian features are cleaning immoral activities, such as stimulants and violence, in modern sports. As for the consciousness of co-existence, green sports integrate civilization and quality, scientific spirits, and ecological ideology into human thoughts, stimulating the focus on "living quality" and "life quality". In perspective of ecology, the green sports reflect the survival and development of competition, co-existence, and independence. The values of green sports admire the green, benefit the nature, and protect the environment with humanism. Apparently, the consciousness of green sports is the fruit of civilization and progress, and the tendency of sports self development. It is a kind of human ecological green in nature, including the functional harmony of nature ecology, economic ecology, and humanities ecology, and the systematic harmony of operational mechanism (Yueliang Ma, 2004). As for the consciousness of volunteer, sports are global activities with the lowest entrance requirement, the most agreements, and the widest participation, and the most general basic activities based on human body. The vitality is the extensive participation of human. Therefore, in the author's opinion, In the process of further driving China develop from sporting giant to sporting power, we should take the mass sports, competitive sports, school sports, sports industry, and sports soft power as the base, and the construction of green sports as the guide, "with general coordinative thoughts and means, overcome the alienation of sporting activity, and reach the general dynamic harmony which includes the harmonies of human 
and nature, people and people, and individual" (Yin Guo \& Zhibin Huang, 2005), realizing the integration of green sports' consciousness, education, system, service, and culture, and construction of sporting power.

\section{The impact of green sports education on construction of sporting power}

Education is the primary goal of Olympic Games established by Coubertin. It is also the backbone of Olympic Games. Since the renaissance in 1896, modern Olympic Games are always insisting to the ideology of "Education", contributing a lot to the healthy and complete development of youth, the world peace, and human social development. According to Articles in Olympic Charter, Olympic education is an important component of Olympic Games. It takes Olympic Games as the carrier, and all people, especially the youth as the education target, conveying Olympic knowledge, values, and life philosophy to the mass, by means of combining sports, culture, and education together. By this way, it helps human to form healthy life style, and drive the harmonious development of body, mind, and social behavior, aiming at realizing the world peace (Jianhua Zhang, Yujie Yuan \& Lulu Niu, 2008, p59). Olympic Games can train participators and influence others to possess the characteristics of braveness, self-control, and progressiveness, and make them take strong responsibility and awareness of rules as life codes, with the special educational function, from the angle of human development and progress, by means of splendid Olympic education, ideal education pursuing for justice and fairness, and spiritual education admiring "solidarity, friendship, peace, and progress" (Dajun Han \& Bingfeng Yan, 2009, p107). For example, during the preparation for Beijing Olympic Games, China works harder than Japan, Korea, America, Spain, Australia: set up 556 Olympic model schools, publicize and promote Olympic idea by a series of activities, and advocate Olympic education, sports spirit education, patriotism education, team spirit education, and other ideological education, and volunteer actions and smile activity, trigger people's consciousness of patriotism, improve the proud of nation, enhance the integration of nation, and attract more and more people join in the Olympic activities. Meanwhile, the host city's superiority and host country's confidence supply immeasurable spiritual legacy for Beijing Olympics (Wei Huang, 2008. p75-76). In an unconscious way, it effectively improves people's quality and social civilization. Patriotism, dedication, credit, and kindness become people's initiative reflection. In displaying Chinese' healthy bodies, positive attitudes, and polite words and behaviors, Olympic Games have shaped good images of country, government, and people. It should be said that the green sports education in China covers the largest area and influences the most people in world history. Therefore, in further promoting China's process from sporting giant to sporting power, we should educate the youth with ecology, including foreign people, integrating oriental natural ecology, economic ecology, humanism ecology, and unity ecological philosophy into the construction of sporting power, driving the cooperation of international technologies and cultures guided by sports, and the transformation of human from industrial society to ecological society.

\section{The impact of green sports system on construction of sporting power}

In China, the sports system is highly unified, which determines the uniqueness and high efficiency of collecting powers to develop sports. In this mode, the government is in charge and makes general plans. It can make best use of national sports resources, apply sports plans according to the general program, and ensure the extensive development of sports to a great degree. For example, the physical legacy, what we can see now, are uprising in Beijing and other associate cities by its Olympic standard, Chinese style and rate, such as the grand stadium, advanced infrastructure of modern cities, and city outlook. However, the most priceless legacy are nothing but the cultivated citizen with modern civilization and quality, the introduced management system with modern meanings and social operation way (Bin Yu \& Zhangwei Song, 2007, p63). In the process of organizing the Olympic Games, Beijing Olympic Organizing Committee carries out an in-depth cooperation with foreign experts, acquiring advanced international experiences, using an international approach to prepare for and hosting the Olympic Games, learning advanced experiences and operation modes from foreign experts in dealing with complex situations. The involvement of foreign experts in the preparation and hosting of the Olympic Games further accelerates the innovation of China system and mechanism, strengthens the transparency of government work, and enhances the supervision of media. This not only helps to establish the new image of China social progress, but also supply useful experiences for China dealing with international issues by following international rules after the WTO entry. During the process of China from sporting giant to sporting power, the government should make best use of opportunities, fulfill the function of supplying public services, grasp the chance of the green Olympic Games, build a relevant system for green sports, and accelerate the process of constructing a sporting power, concerning with the fields of mass sports, competitive sports, school sports, sports industry, and sports soft power. 


\section{The impact of green sports service on construction of sporting power}

The 30-year development of market economy makes the government give up the right of supplying private products to the society. The administrative power is responsible for the production of public services. However, facts in Wenchuan Earthquake prove that public services can also be provided by the folk society, instead of being provided exclusively by administrative power. For this issue, what happened after the Wenchuan Earchquake is a nice start. The Olympic Games can make a new breakthrough. In the construction of Beijing Olympic stadium, social investment accounts for the half of total investment. By means of market financing, government investment, and the combination of the two, the government does not necessarily worry about the high operation expenses for stadium (Wei Huang, 2007, p66-67). Meanwhile, enterprises can find the platform from the government's market exploration, and participate in public biding by corporate association, controlling the idle issue of Olympic stadium to a reasonable degree by means of investment and operation. Community sports are influencing people due to its popularization, and become an irreplaceable part of daily life (Yansheng Zhong, 2008, p1152-1156). That is the most valuable legacy of green sports service from Olympic Games. Just as what was said by an International Olympic Committee, the Olympic legacy is firstly people, who join in and pay close attentions to Olympic Games. Their presence will pass the influences of Olympic Games from one generation to another generation. The mass sports, as the legacy of green Olympic Games, reflect China's pride and glory, and play an important role. In further promoting the process of China from sporting giant to sporting power, we should emphasize on the values and benefits of mass sports. Meanwhile, the nation and the society should make common efforts to drive the development and progress of mass sports, make green sports services benefit folks, close to their daily life, and help Chinese shake off the sub-health state. Furthermore, in order to construct a sporting power, we must develop mass sports, and take people's needs for sports as a priority according to the people-oriented rule. We should guarantee everyone the access to public sports and take mass sports as a part of social service.

\section{The impact of green sports culture on construction of sporting power}

According to an statement from United Nations Educational, Scientific and Cultural Organization (UNESCO): "Development can be defined by the concept of culture ultimately. The prosperity of culture is the highest goal of development." Fashion does not deny tradition. The pursuit for tradition is also a fashion. Some fashions are fleeting, and some last. The root is the culture, the national spirit. Creation is the spirit of national progress, and the eternal energy for the prosperity of nation. People enjoy culture, and also operate and create culture. Culture enjoyment, culture relaxation, culture entertainment, culture investment, and culture collection are the inevitable outcome of economic development. Cultural creative industry takes culture as the theme, innovation as the core, and industrial development as the energy. It aims at promoting the prosperity and development of cultural industry and make people share cultural achievements. To develop the sports cultural creative industry is a new thought for driving the development of sports. Although China is a developing country, it is at an important industry-structure-transform period. In Beijing's city planning outline, the development and livable city are the priority of city planning. And it is an organic combination of hard power and soft power. The statement of "two axes, two belts, and multiple centers" completely indicates a new spatial arrangement and industrial layout. Here, it must be emphasized that, for city planning, innovation is not to overturn the original things thoroughly but inherit and develop national culture, catching up with the development of times (Yi Zhao, 2008, p82). In further promoting the process of China from sporting giant to sporting power, we must be scientific, forward-looking, and creative, with the guidance of scientific concept of development, develop and use the green sports cultural legacy of Beijing Olympic Games, develop the education effect of green sports cultural legacy and the multiple function of cultural legacy, make full use of Olympic stadium, explore its maximum benefits after the Olympic Games, and build a new pattern for green sports cultural creative industry, which includes the public ownership as the main body and various forms of ownership as participators.

\section{References}

$\mathrm{Bu}$, Te. (2007). Harmonious PE: back of nature of PE. Journal of Inner Mongolia Normal University (Philosophy and Social Science), No. 36(4), p.95-100.

Guo, Yin \& Huang, Zhibin. (2005). Introduction to Green Culture and Green Aesthetics. Hefei: Anhui People's Publishing House.

Han, Dajun. \& Yan, Bingfeng. (2009). The promotion of research of culture-enrich Olympics and Olympic cultural legacy. Oriental Forum, No. 1, p.107.

Huang, Wei. (2008). Thoughts on Olympic legacy. Invest Beijing, p75-76. 
Jin, Houzhong. Bu, Te \& Hua, Yongmin. (2009). Green PE in perspective of ecological philosophy. Journal of Beijing Sport University, No. 4, p.23.

Ma, Yueliang. (2004). A reflection about the modern sport in the evolution of civilization. Sports Culture Guide, No. 2.

Qiu, Xue. (2010). The establishment of target system for strong sporting nation. China Sport Science and Technology, No. 46(1), p.10-14.

Yu, Bin. \& Song, Zhangwei. (2007). Research on Beijing Olympic legacy after 2008 ------ strategies for improving the efficiency of facilities in use in Olympic venues. Oriental Enterprise Culture, No. 11, p.66-67.

Zhang, Jianhua. Yuan, Yujie \& Niu, Lulu. (2008). Research on the connotation of Olympic educational legacy. Sports Culture Guide, No. 6, p.59.

Zhao, Yi. (2008). Thoughts on develop the travel value of Olympic legacy. Invest Beijing, p.82.

Zhong, Yansheng. (2008). Integrate the ideology of Olympics into community life ------ Olympic Sports drives the construction of harmonious community. Chinese Journal of Management Science, p.1152-1156. 